\title{
Four Core Concepts in Psychiatric Diagnosis
}

\author{
Leonardo Zaninotto ${ }^{a, b}$ Andrea Altobrando ${ }^{b, c}$ \\ aDepartment of Mental Health, Local Health Unit no. 6 ("Euganea"), Padova, Italy; ${ }^{b}$ Noumenon Research Center, \\ University of Padova, Padova, Italy; ' Department of Philosophy, Sociology, Education and Applied Psychology, \\ University of Padova, Padova, Italy
}

\section{Keywords}

Diagnosis · Empathy · Phenomenology · Psychopathology · Subjectivity

\begin{abstract}
In the present article, we aimed at describing the diagnostic process in Psychiatry through a phenomenological perspective. We have identified 4 core concepts which may represent the joints of a phenomenologically oriented diagnosis. The "tightrope walking" attitude refers to the psychiatrist's ability to swing between 2 different and sometimes contrasting tendencies (e.g., engagement and disengagement). The "holistic experience" includes all those intuitive, nonverbal, and pre-thematic elements that emerge in the early stages of the clinical encounter as an emanation of the atmospheric quality of the intersubjective space. The "co-construction of symptoms" regards the hermeneutic process behind psychiatric symptoms, involving both the patient as a self-interpreting agent and the clinician as a translator of his/her experience. Finally, by the "evolving typification" we mean that the closer the relationship becomes with the patient, the more specific and nuanced becomes the typification behind psychiatric diagnosis. Each of these concepts will be accompanied by an extract from a clinical case deriving from one of the authors' most recent clinical experiences.
\end{abstract}

(c) 2021 S. Karger AG, Basel

karger@karger.com

(c) 2021 S. Karger AG, Basel

www.karger.com/psp

Karger!

\section{Introduction}

In Medicine, by the term "symptoms" we refer to the patient's subjective complaints, whereas by "signs" we refer to those observable phenomena coming from the patient's body. They both point at a somatic disease, meant as a natural entity, with its causes, course, and prognosis. Diagnostic reasoning in somatic Medicine may be compared to completing a puzzle [1], by matching the information obtained from the patient with the evidence deriving from physical examination, laboratory investigations, and diagnostic imaging.

Conversely, in Psychiatry, symptoms and signs both involve a subjective component, since behavioral signs are meant as expressive, in so far as they point at a meaningful complex of emotional, cognitive, and bodily phenomena [2]. In recent years, several theoretical models have been developed to describe diagnostic thinking and clinical decision-making in Psychiatry $[1,3-6]$. With few exceptions $[1,4]$, most of them tend to reproduce a modified version of the medical model, where diagnosis is conceived as an individual, cognitive process aimed at categorizing the patient's problem according to some predefined diagnostic criteria.

In the present article, we aimed at identifying and describing some core features of the diagnostic process in Psychiatry through a phenomenological perspective. 
Our assumption is that the inherently ambiguous nature of the psychiatric object, suspended between empirical difficulties and problems of meaning $[7,8]$, requires a "disciplined spontaneity" [9] to the clinician, a sort of epistemological and methodological turn, characterized by being more sensitive to the role played by subjectivity (of both the patient and the clinician) than to the objective approach of Medicine, more prone to understanding than to verifying and more person-centered than morbus-oriented [10]. For that purpose, we have identified 4 core concepts derived from the phenomenological literature, which we synthetically named (1) the "tightrope walking" attitude, (2) the "holistic experience," (3) the "co-construction of symptoms," and (4) the "evolving typification." Each of these concepts will be accompanied by an extract from a clinical case deriving from one of the author's most recent clinical experiences.

\section{Psychiatry as a Tightrope Walking Exercise: The Methodological Lesson by Karl Jaspers}

The theoretical framework for psychiatric diagnosis is represented by the discipline of Psychopathology, which can be basically defined as a theory and a method (logos) to deal with the sufferings (pathos) of human mind in its subjective dimension (psyche) [11]. The European tradition of Psychopathology has one of its major representatives in Karl Jaspers [12] (1883-1969), whose monumental "General Psychopathology" moved from Husserl's lesson on the phenomenological method to address the issue of exploration and systematic conceptualization of psychopathological phenomena. The core concept in his work was represented by the notion of "methodological consciousness" [13], by which he meant a definition of the targets, the methods, and the limits of psychopathology.

As regards the diagnostic process, the most important methodological issue regards the distinction between "explaining" (Erklären), which belongs to the natural sciences (Naturwissenschaften), and "understanding" (Verstehen), which is proper of the human sciences (Geisteswissenschaften) [13]. According to Jaspers, both explaining and understanding are necessary to the psychopathologist since the psychiatric object asks for a sort of "binocular vision," a methodological dualism based on both causally compelling, generally valid explanations, and subjective, intuitive, empathic understanding. Explanations aim at exploring the causal relationships between events to find a general rule, and they serve the diagnostic process by addressing the clinician toward specific routes of investigation.

A young woman came to the outpatient service after a 2-week hospitalization for an acute psychotic episode. She reported a personal history of physical abuse and parental loss during childhood and adolescence (her father was described as violent and abusive; he left the family when she was 10) and a family history of mood disorders (her mother suffered from bipolar disorder). Both these features have been consistently associated to a higher risk of psychosis [14, $15]$.

In this case, facts are observed by a third-person perspective so that they can be generalized and subjected to empirical verification: the clinician can hypothesize connections among facts based on epidemiological research and then verify them by including an external source of information, e.g., by interviewing another family member.

Conversely, understanding regards all those psychic events that need to be caught by a sort of intuitive process based on a "common experiencing" (Miterleben) between the clinician and the patient [16]. The process of understanding is based on cultivating empathy for the patient's experiences by a first-person perspective [17], namely, by trying to "actualize" in one's own consciousness what the patient's words, bodily expression, and behavior are conveying about him/her. This is the first form of understanding, defined as "static," which gives a transversal depiction of the psychic phenomena in the here and now.

During the interview, the woman recalled that a few weeks before hospitalization, she started having some very vivid dreams, which she ended "confusing with reality." She also experienced some synesthetic phenomena (e.g., a color came to her mind after hearing a sound) and transitivistic experiences (e.g., she could feel the same physical pain as her friends). There was no explicit delusional explanation about these phenomena, though she felt as having a sort of special connection with people and things. Sometimes she happened to vividly perceive the "will" of other people as an almost physical quality coming upon her, but with no real influence on her thoughts and actions. She denied experiences of thought influence/insertion or thought diffusion. However, she recalled being inclined to do things without being fully "present" to herself, as if she were living in a sort of "trance," and that her thoughts used to flow rapidly and incessantly, being moved by her shifting emotions and "creative" associations.

Thus, diagnosing in Psychiatry requires the clinician to walk the tightrope that ideally leads to an empathic and unprejudiced acquaintance with the patient's experience, while at the same time trying to avoid the dangers and pitfalls of either cold, detached objectification or fusional overidentification. This exercise requires not only an 
ability in distance modulation [18] but also the capacity to swing constantly between explaining and understanding, between a detached 3rd person observation and an engaged 1st person envisioning, and finally between basic, preverbal, empathic intuition and a theoretically oriented critical thinking, addressed to verifying that intuition through empirical observation, consequential reasoning, and comparison with psychopathological constructs [19].

\section{The Holistic Experience of First Impressions}

A reappraisal of the role of clinical intuition has recently been called from many parts as essential for the development of a theoretically consistent conceptualization of psychiatric diagnosis [3, 20,21]. One of the most famous theoretical views about the role of the clinician's early impressions is represented by the concept of the praecox feeling, developed by the Dutch psychiatrist H.C. Rümke [22]. In his article, Rümke and Neeleman [23] state that while meeting with a schizophrenic patient for the first time, "even after a brief mental state examination, it becomes clear to the psychiatrist that his empathy is lacking" (, p. 336). It is a rather immediate, preverbal, and global experience based on a sort of "undefinable attribute" surrounding the person, more than on an explicit listing of signs and symptoms [23, 24]. It is this holistic quality that adds specificity to the diagnosis of schizophrenia since the gestalt character of some mental symptoms, especially when dealing with major psychoses, refers to some implicit "core" change in the fundamental structure of the patient's subjectivity $[10,25]$.

The praecox feeling may have some features in common with the so-called atmospheric feelings, which seem to emerge in the early stages of the clinical encounter as an emanation of its intersubjective space. The same praecox feeling has been conceived as an in-between event, namely as a specific quality of the relationship between the psychiatrist and the schizophrenic patient [26]:

When meeting the woman for the first time, the clinician already had some information about the clinical presentation and the course of the acute episode. Clinical records gave him a generic description of a typical psychotic breakdown (emotional lability, agitation and insomnia, bizarre behavior, cognitive disorganization, and delusional thought contents based on transitivistic experiences). The woman had been treated with medium-to-high doses of an atypical antipsychotic, which gave her a series of cognitive, emotional, and neurological side effects (a sense of cognitive "numbing," emotional flattening, and tremor). A colleague from the inpatient service assumed that the woman was affected by a schizophrenia spectrum

Four Core Concepts in Psychiatric Diagnosis disorder. However, no sensation of lack of contact, bizarreness, or affective distance emerged from their first encounter. On the contrary, though the effect of psychotropic medications might have altered the quality of contact, the psychiatrist felt a sense of warm closeness to the patient, a sort of a nonsexualized seductive atmosphere, as if she was a child asking for protection and assurance.

Atmospheric perception is supposed to be a rather immediate, preverbal, and unconscious experience based on symptomatically informative hints like the gaze, the walk, the presence of involuntary movements, or even the phono-symbolic and metaphorical value of words used by the patient to describe his/her experiences [27]. Different phenomenological authors have recognized a kind of atmospheric participation in clinical diagnosis: Tellenbach's [28] "atmospheric diagnosis," Minkowski's [29] "diagnostic par pénétration," Binswanger's [30] "diagnosis by feeling," Wyrsch's [31] "diagnosis by intuition," and Schneider's [32] "knowledge through the relationship" all seem to refer to similar experiences.

Despite different names, at least 3 common features can be detected across those conceptualizations: (a) the intuitive, immediate, and pre-reflective nature of the process, which can be traced back to the realm of the lived body and lived space; (b) its openness to thematic knowledge and verbal communication; and, above all, (c) the supposed intersubjective nature of its contents, where the perceiver/perceived distinction somehow seems to vanish [33], and the phenomena are conceived by a secondperson perspective. Whenever we start engaging with somebody, we are immediately involved into a shared space, where our thoughts, emotions, and actions need to adapt and change according to the ongoing dialogical situation. This way of conceiving social interaction is mainly modeled on Gibson [34]'s notion of "affordances" [35]. Affordances are species-specific action possibilities, offered to the animal by its own environment, guiding its perceptions and actions toward goals and values, and shaping the same environment accordingly. In face-toface social interaction, vocal acts, gestures, facial expressions, bodily postures, and even the way of inhabiting space (e.g., by moving incessantly or by standing tense and motionless) become reciprocal affordances, guiding the development of a dynamic action-perception circle, allowing cognition and emotion to emerge, and creating a shared space of meaning [35].

In the early moments of a face-to-face encounter, when the nascent perception of the other arises from the level of affective experience [36], part of this process may run through the immediate and unconscious pathways of shared emotions. According to Scheler [37] (1874-1928), 
our ability to directly grasp other's feelings has its foundation in a primordial form of human sympathy, which he calls emotional unity (Einsfühlung). Scheler maintains that there are some emotional experiences, such as vital feelings (Vitalgefühl) and psychic feelings (seelische Gefühle), which can be directly and immediately shared among human beings in a sort of emotional pre-communication. This is supposed to happen based on an unconscious and pre-thematic pathway, moving from a sphere before, and beyond, the I-Thou distinction and emanating from that "original and inseparable unity of perception, intentionality, and expressive behavior" [38] represented by the living body. In other words, emotions and intentions are immediately and directly perceived in interaction by a second-person perspective [39], based on the pre-reflective intentional connection between living bodies $[40,41]$.

When meeting a patient for the first time, the clinician will sometimes find him/herself as irreflexively, immediately permeated by a new, different emotional condition. This experience may vary in both intensity and quality, depending on the information the clinician was given about the patient, the features of the "scene" and of its protagonists, the presence of favoring or confounding factors, and the sensibility and experience of the clinician.

\section{From Basic Empathy to Genetic Understanding: The Co-Construction of Symptoms}

According to the phenomenological perspective, talking about psychiatric diagnosis without facing the core question of empathy is like waiting for a plane at the train station, i.e., simply missing the point. A comprehensive account of the debate about empathy and social cognition is beyond the scope of this article (for an overview, see [42]). However, a few key points from this debate may serve our purpose of describing how an encounter between 2 people can result into a (diagnostic) typification.

The first key point regards the perceptive-expressive roots of empathy, the so-called basic empathy [43]. The phenomenological tradition conceives empathy as a perceptually based experience of the other's mental life [37, 44-46], where humans are temporalizing and moving organisms [47], whose intentions and emotions are embodied in their behavior in a meaningful "expressive unity" (Ausdruckseinheit) [37]. As a consequence, preverbal, immediate, "sympathetic communication" between humans is based on the continuous and dialogical interaction between perception and movement [48], where the interacting subjects take each other's expressive actions as affordances for further complementary actions [49, 50].

Another prerequisite of empathy is the self-other distinction. There is a fundamental asymmetry between my experience and the other's experience. Other's subjectivity is suspended between immanence (i.e., being embodied in his/her expressive behavior) and transcendence (i.e., being partially inaccessible to my direct perception) [50], making empathic apprehension a sort of asymptotic process, where the other is somehow near but also elusive, discernible but never fully understood.

This fundamental asymmetry becomes particularly relevant when dealing with the suffering subject. In both Medicine and Psychiatry, the purpose of empathy is to fill the gap between the experience of the patient, living the illness from within, and the viewpoint of the clinician, divided between affective resonance and rational distance. The illness experience itself involves a radical transformation of subjectivity, where the subject becomes a multilayered and complex entity (i.e., a living and suffering subject having a specific experience of the world, the body, and the self), requiring a multidimensional approach to understanding [51].

Here comes the third key point about empathy. In some situations, such as a face-to-face clinical encounter, empathic understanding needs to go beyond the level of spontaneous and perceptual experience to become a dynamic and pragmatic process, entailing also some purposive or voluntary elements [52]. Under these circumstances, the clinician usually supplements the spontaneous affective resonance of basic empathy with some higher order strategies, often named as "cognitive empathy" [53], aimed at providing him/her with a more comprehensive overview of the patient's experience.

In recent years, Edith Stein's (1891-1942) multidimensional approach to empathy has received new consideration $[54,55]$. In her view, empathy not only occupies somehow an ambiguous position, being similar to perception in "originally" presenting the other's living body in a direct, unmediated way, but also close to other (nonoriginal) forms of experience, such as "memory, expectation, and fancy (imagination)" ([45], p. 8), in that the other's own experiences are not given immediately and directly. Stein's account of empathy includes a 3-step process, where: (1) the other's thoughts, perceptions, feelings, and intentions are immediately perceived as a meaningful complex (the emergence of the experience), about which (2) I fulfill an explication by an imaginative account (the fulfilling explication), in order to (3) return to 
a more comprehensive understanding of the whole experiences of the other (the comprehensive objectification) $[45,52,55]$.

When empathy reaches its pragmatic dimension, calling for a deeper engagement of the empathizing subject, the experience of the other goes beyond basic, immediate, and purposeless perception to become the object of a cognitive task aimed at recalling one's personal experiences and knowledge of common sense meaning to build an imaginative account of the other's mental life, even in its most uncommon and ambiguous expressions. At this level, both theorizing (i.e., drawing on our theoretical knowledge about the disorder and its clinical features) and imaginative perspective taking (i.e., recollecting personal memories about similar experiences) [56] may serve the purpose of grasping the experiential situation of the subject suffering from a mental disorder.

In diagnostic decision-making, the need-interest that moves the pragmatic process of cognitive empathy corresponds to the clinical endeavor of the psychiatrist: what we could call his/her "attuned interest" $[52,57]$ for the patient's experience of suffering and alienation. This purposive attitude might drive his/her attention from the implicit second-person and first-person stances of early atmospheric feelings and basic empathy to an explicit thirdperson perspective based on different faculties, such as memory, expectation, and imagination. This shift in perspective is also representative of the methodological pluralism of Psychiatry, and it becomes particularly relevant when turning from a first-person immersion into understandable experiences of suffering to a third-person imaginative account about the most severe and incomprehensible psychopathological phenomena.

According to Jaspers [13], we may be able to reach a first-person (static) understanding of many kinds of experiences, even those which may involve a lack of contact with reality, such as falsification, deception, "neurotic" reactions, and even melancholic delusions (which he considered as pseudo-delusions). But our empathic intuition must necessarily stop when facing the elementary nature of organic illness and psychosis, where, by the term "psychosis," Jaspers mainly refers to the group of schizophrenias. He considers certain schizophrenic phenomena, such as delusional mood (Wahnstimmung), delusional perceptions (Wahnwahrnehmungen), and delusion proper, as "(statically) incomprehensible," since they can only be described "by what they are not" [13].

We believe that, for mental health professionals, a fruitful and pragmatic attempt to expand the limits of Jaspers' understanding may be based on 2 standpoints. The

Four Core Concepts in Psychiatric Diagnosis first one is based on the assumption that delusion proper and other "primary" symptoms are understandable responses to more elementary unusual experiences, such as the so-called basic symptoms $[58,59]$ or, more generally, to a disturbed Self-experience $[60,61]$. Both basic symptoms and Self-disorders are supposed to be the most primitive experiences that precede other secondary symptomatic dimensions, such as delusions and complex hallucinatory phenomena (i.e., "hearing voices"). In recent years, several empirical studies have shown that basic symptoms are associated to a higher risk for psychotic disorders [62, 63], while Self-disorders are specific of the schizophrenia spectrum [64-66].

From this standpoint, the border of incomprehensibility is moved from full-blown psychotic symptoms to the higher order dimension of basic symptoms and Self-disorders, where delusion proper and other "primary" phenomena are seen as a comprehensible elaboration of the latter [67]. In the phenomenological perspective, the patient is viewed as a self-interpreting agent, having an active role in interacting, shaping, and making sense of his/ her own symptoms [68]. Thus, a skilled clinician having a good imaginative attitude may be able to gain true genetic understanding over the whole psychopathological sequence, starting from basic symptoms and Self-disorders, incorporating biographic and emotional elements, and finally landing on the delusion proper.

The second perspective can be summarized by the icastic words of one of the "founding fathers" of Italian psychopathology, Arnaldo Ballerini [69]: "delusion is never understandable, but a delusional individual can be deeply understood" (p. 19). Indeed, while some pathologic experiences have an undeniable facade of formal incomprehensibility, both the biographical contents and the emotional core of those experiences may become object of attention depending on the consistency, deepness, and duration of the therapeutic relationship [70]. According to this perspective, another strategy of cognitive empathy might be the one of "openness" [56]: in the attempt to develop a more comprehensive understanding of the patient's experience, the clinician invites the patient to express him/herself more fully and accurately.

According to Jaspers [13], a second form of understanding, defined as "genetic," allows us to perceive the meaning of psychic connections and to understand the way psychic events emerge out of each other - i.e., how certain thoughts rise from moods, wishes, or fears - from the viewpoint of the motivational chain (meaningful connections) [71]. But a true psychological understanding 
can only result from a complex hermeneutic process involving both the patient as a self-interpreting agent and the clinician as a "translator" of what the patient is trying to communicate [72].

After a few visits, a theme emerged from the young woman's account. During the episode, she felt a strong connection with a person she had known years before. She felt "as if" she could know everything he was doing, feeling, or thinking. It was an older man she had been secretly in love with when she was a young intern in his company. Nothing had happened between them, but she had treasured this secret for years. She recalled comparing him to her father, who also was a powerful and charismatic man and figuring him as an idealized version of her abusing and abandoning parent.

\section{Psychiatric Diagnosis as an Evolving Typification}

The elements that may become subjects for the diagnostic process are virtually infinite. There is a need for the clinician to establish a perspective based on some cultural values and need-interests $[73,74]$, which in this case are represented by both the theoretical background of Psychopathology and the desire for an in-depth understanding of the patient's experience. This perspectival knowledge is usually accompanied by a sort of pre-comprehension of the other's mind, which sets a rudimental framework for the subsequent process of genetic understanding. Both Husserl and Stein supported the view that a person has a pervasive and individual style: "A person has, in the broadest sense, a typical character and properties of character. Everything a person lives through enlarges the framework of his pre-givennesses, can emerge again in memory whether clearly or obscurely, can affect the ego, and motivate actions" ([75], p. 271).

Thus, empathic understanding presupposes not only our "attuned interest" but also a pre-comprehension of the other based on a constitution of types or examples, involving features of personality and values. This precomprehension is based on the stratification of our emotional life as well as of our past experiences, beliefs, and habits [55]. In the case of psychiatric diagnosis, it must include both an acquaintance with the concepts of Psychopathology and the "weight" of clinical experience with similar cases. An ideal type is a sort of "pure" case in which the relevant features are invariant, unambiguous, and clearly discernible and can be grouped together by a specific perspective $[73,76]$.

The woman recalled living her experiences of transitivism with a strong affective participation in a sort of dream-like atmosphere. Further, some phenomena, such as the "flight of ideas," the sleep deprivation, and a general impression of easiness and smoothness - including a sense of amplification and facilitation of perceptions suggested a maniform component. Drawing from his theoretical knowledge and recalling similar cases, the psychiatrist hypothesized that the woman had experienced a brief psychotic episode in the context of a probable vulnerability to mood disorders and dissociative disorders and changed her treatment by minimizing the antipsychotic dose while introducing a mood stabilizer. Those changes produced an almost immediate beneficial effect on most of the cognitive, emotional, and motor symptoms and significantly improved her sense of well-being.

If we consider the diagnosis as a target, the ideal typical approach is above all looking at the center of the target (the ideal type), while the operational approach is more interested to the boundaries of the target (the inclusion/ exclusion criteria) [18]. However, the ideal typical approach can be considered complementary to operational diagnosis since defined categories and diagnostic criteria become meaningful only when used by somebody who can already identify and distinguish mental disorders in the way of "typification" [77].

At the beginning of the clinical encounter, the clinician will initially sense the patient's attitude in a very basic, rudimentary way, i.e., as being sympathetic, hostile, suspicious, or uncanny. Atmospheric diagnosis and the abovementioned experience of the "praecox feeling" may also be regarded as early forms of typification [77]. Then, this first preconceptual, unconscious, "atmospheric" impression becomes thematic and conceptually explicit, enriched by further reflection about the information provided by the patient, by any other source, and by what his/ her symptoms tend to express. Typification is then called into question and tested by evidence. Ideal types are necessary because they guide the clinician in discriminating what is relevant and what is irrelevant, what is typical and what is atypical in the patient. They pre-delineate the kinds of questions that require further investigation in a particular case [74]. This is the sense of the "hermeneutic circle," where our typification is confronted and verified with data driven from experience. This is the way typification becomes scientific [78]. Then, the closer the relationship becomes with the patient, the more specific and nuanced become typifications. Diagnostic reasoning in Psychiatry may then be compared to drawing a portrait of the patient, starting from a "static" sketch of his/her elementary psychopathological experiences, adding more and more details as the clinician gets to know the patient's history and experience, and finally building a comprehensive view of the psychopathological picture according to ideo-typical entities [79]. 


\section{Conclusion}

Clinical reasoning, both in Medicine and Psychiatry, is a complex process that goes through a series of cognitive "transfer stations" [80], where a provisional diagnostic label needs to be verified by empirical observation in order to guide subsequent reasoning toward a valid diagnostic conclusion. In the case of Psychiatry, the clinician must go even further, by the application of that "methodological consciousness" ( [13], p. 44), which is supposed to allow him/her to dialectically "swing" between 2 opposite positions.

First, in diagnostic decision-making, the psychiatrist must constantly balance engagement with disengagement, true empathic understanding with detached explaining, where the dimension of disengagement and detachment represents the dialectical counterpart of engagement. Second, good diagnostic reasoning needs to involve both pre-reflective, immediate apprehension and reflective, mediated information processing. In other words, it requires what dual-process theories $[81,82]$ describe as the two interrelated systems of human cognition, the intuitive and the analytic system [83]. The clinician needs to exert his/her intuitive system in order to grasp the contextual features (i.e., the Gestalt) of the clinical encounter, in order to generate the hypotheses (i.e., the ideal-type) that feed into the analytic approach and need to be tested by a hypothetico-deductive methodology [1].

Third, the psychiatrist needs to learn how to "swing" between a direct, second (or first)-person immersion and a detached, third-person observation. The clinician is obviously loaded with experiences, as well as ideas and preconceptions about his/her own profession. What is required by a true phenomenological approach to diagnosis is that he/she must learn to take off - at least temporarily - all his/her Ideenkleid, to give space to a direct, unmediated, pre-theoretical experience of the suffering subject. However, in order to explain and describe this experience, the phenomenological attitude needs to refer to those same ideas and preconceptions that it had to discharge. In other words, the phenomenological attitude proceeds in a sort of back-and-forth movement $[84,85]$, going from the pure experience to the pre-given concepts and then again from the concepts to the experience itself, in order to describe it and make it clear to consciousness [86].

\section{Statement of Ethics}

The paper is exempt from Ethical Committee approval, being based almost exclusively on the published literature. Written informed consent was obtained from the patient for publication of the clinical vignettes from the case report.

\section{Conflict of Interest Statement}

The authors have no conflicts of interest to declare.

\section{Funding Sources}

The publication of this article has been supported by the research project FACC_BIRD2121_01, FISPPA-Department, University of Padova.

\section{Author Contributions}

Both authors contributed equally to the conception, writing, drafting, and revising of the paper.

\section{References}

1 Gupta M, Potter N, Goyer S. Diagnostic reasoning in psychiatry: acknowledging an explicit role for intersubjective knowing. Philos Psychiatry Psychol. 2019;26(1):49-64.

2 Nordgaard J, Sass LA, Parnas J. The psychiatric interview: validity, structure, and subjectivity. Eur Arch Psychiatry Clin Neurosci. 2013;263(4):353-64.

3 Srivastava A, Grube M. Does intuition have a role in psychiatric diagnosis? Psychiatr Q. 2009;80(2):99-106.

4 Fuchs T. Subjectivity and intersubjectivity in psychiatric diagnosis. Psychopathology. 2010;43(4):268-74.
5 Fernando I, Cohen M, Henskens F. A systematic approach to clinical reasoning in psychiatry. Australas Psychiatry. 2013;21(3):224-30.

6 Morrison J. Diagnosis made easier: principles and techniques for mental health clinicians. 2nd ed. New York: Guilford Press; 2014.

7 Cargnello D. Ambiguità della Psichiatria. Comprendre. 1999;9:7-48.

8 Markovà IS, Chen E. The hybrid structure of psychiatry. Dial Phil Ment Neuro Sci. 2020; 13(2):36-42.

9 Giorgi A. Phenomenology and psychological research. Pittsburgh, PA: Duquesne University Press; 1985.
10 Kraus A. Phenomenological and criteriological diagnosis: different or complementary? In: Sadler J, Wiggins O, Schwartz M, editors. Philosophical perspectives on psychiatric diagnostic classification. Baltimore: The John Hopkins University Press; 1994. p. 148-60.

11 Stanghellini G. The meanings of psychopathology. Curr Opin Psychiatry. 2009;22(6): 559-64.

12 Jaspers K. Allgemeine Psychopatologie. 1st ed. Berlin: Springer-Verlag; 1913.

13 Jaspers K. Allgemeine Psychopathologie. 7th ed. Berlin: Springer-Verlag; 1959. 
14 Varese F, Smeets F, Drukker M, Lieverse R, Lataster T, Viechtbauer W, et al. Childhood adversities increase the risk of psychosis: a meta-analysis of patient-control, prospectiveand cross-sectional cohort studies. Schizophr Bull. 2012;38(4):661-71.

15 Van Snellenberg JX, de Candia T. Meta-analytic evidence for familial coaggregation of schizophrenia and bipolar disorder. Arch Gen Psychiatry. 2009;66(7):748-55.

16 Jaspers K. Die phänomenologische Forschungsrichtung in der Psychopathologie. Zeitschr ges Neurol Psychiat. 1912;9(1):391-408.

17 Fuchs T. Phenomenology and psychopathology. In: Gallagher S, editor. Handbook of phenomenology and cognitive science. Dordrecht: Springer; 2010. p. 546-73.

18 Ballerini A. La diagnosi in Psichiatria. Roma: Carocci Editore; 1997.

19 Lanteri-Laura G. Psychiatrie et connaissances. Paris: Sciences en situation; 1991.

20 Parnas J. A disappearing heritage: the clinical core of schizophrenia. Schizophr Bull. 2011; 37(6):1121-30.

21 Pallagrosi M, Picardi A, Fonzi L, Biondi M. Psychopathological dimensions and the clinician's subjective experience. In: Biondi $\mathrm{M}$, Pasquini M, Picardi A, editors. Dimensional sychopathology. Berlin: Springer; 2018. p. 267-86.

22 Rümke HC. Das Kernsymptom der Schizophrenie und das "Praecoxgefuhl". Zentralb Gesamte Neurol Psychiatrie. 1941;102:168-9.

23 Rümke HC, Neeleman J. The nuclear symptom of schizophrenia and the praecoxfeeling. Hist Psychiatry. 1990;1(3 Pt 3):331-41.

24 Moskalewicz M, Schwartz MA, Gozé T. Phenomenology of intuitive judgment: praecoxfeeling in the diagnosis of schizophrenia. AVANT. 2018;9(2):63-74.

25 Stanghellini G, Rossi R. Pheno-phenotypes: a holistic approach to the psychopathology of schizophrenia. Curr Opin Psychiatry. 2014; 27(3):236-41.

26 Gozé T, Naudin J. Discussing Rümke’s “praecox feeling" from the clinician's experience of schizophrenic contact. Psicopatologia Fenomenológica Contemporânea. 2017;6(2): 112-23.

27 Griffero T. The Invasion of felt-bodily atmospheres: between pathic aesthetics and psychopathology. In: Francesetti TG, editor. Psychopathology and atmospheres neither inside nor outside. Newcastle upon Tyne: Cambridge Scholar; 2019. p. 6-34.

28 Tellenbach H. Geschmack und Atmosphäre. Medien menschlichen Elementarkontaktes. Salzburg: O. Müller; 1968.

29 Minkowski E. La schizophrénie. Paris: Editions Payot \& Rivages; 1927.

30 Binswanger L. Welche Aufgaben ergeben sick für die Psychiatrie aus den Fortschritten der neueren Psychologie? Zeitschr ges Neurol Psychiat. 1924;91(1):402-36.
31 Wyrsch J. Über die Intuition bei der Erkennung des Schizophrenen. Schweizerische Medizinische Wochenschrift. 1946;46:11736.

32 Schneider K. Wesen und Erfassung des Schizophrenen. Zeitschr ges Neurol Psychiat. 1925;99(1):542-7.

33 Costa C, Carmenates S, Madeira L, Stanghellini G. Phenomenology of atmospheres. The felt meanings of clinical encounters. Psychopathology. 2014;20(4):351-7.

34 Gibson JJ. The ecological approach to visual perception. Boston: Houghton Mifflin; 1979.

35 Jensen TW, Pedersen SB. Affect and affordances: the role of action and emotion in social interaction. Cogn Semiot. 2016;9(1):79103.

36 Churchill SD. On the empathic mode of intuition. A Phenomenological Foundation for Social Psychiatry. In: Englander M, editor. Phenomenology and the social context of psychiatry social relations, psychopathology, and Husserl's philosophy. London: Bloomsbury Academic; 2017. p. 64-93.

37 Scheler M. The nature of sympathy. London: Routledge \& Kegan Paul; 1954.

38 Schloßberger M. Max Scheler. In: Szanto T, Landweer $\mathrm{H}$, editors. The Routledge handbook of phenomenology of emotions. Abingdon: Routledge; 2020. p. 72-85.

39 Gallagher S. Direct perception in the intersubjective context. Conscious Cogn. 2008; 17(2):535-43.

40 Thompson E. Mind in life: biology, phenomenology, and the sciences of mind. Cambridge, MA: Harvard University Press; 2007.

41 Gallagher S. The practice of mind: theory, simulation or interaction? J Conscious Stud. 2001;8:83-107.

42 Zahavi D. Self and other: exploring subjectivity, empathy, and sharing. Oxford: Oxford University Press; 2014.

43 Fernandez AV, Zahavi D. Basic empathy: developing the concept of empathy from the ground up. Int J Nurs Stud. 2020;110:103695.

44 Husserl E. Cartesianische Meditationen und Pariser Vorträge, Husserliana, Bd. I. Den Haag: Martinus Nijhoff; 1950.

45 Stein E. On the problem of empathy. Washington, DC: ICS Publications; 1989.

46 Merleau-Ponty M. Phenomenology of perception. Abingdon: Routledge \& Kegan Paul; 1962.

47 Straus E. Von Sinn der Sinne. Berlin, Gottingen, Heidelberg: Springer; 1935.

48 Weizsäcker V. Der Gestaltkreis. Theorie der Einheit von Wahrnnehmen und Bewegen 4. Aufl. Stuttgart: Georg Thieme Verlag; 1950.

49 Zahavi D, Michael J. Beyond mirroring: 4E perspectives on empathy. In: Newen A, De Bruin L, Gallagher S, editors. The Oxford handbook of 4E cognition. Oxford: Oxford University Press; 2018. p. 589-606.

50 Krueger J. Direct social perception. In: Newen A, De Bruin L, Gallagher S, editors. The Oxford handbook of $4 \mathrm{E}$ cognition. New York: Oxford University Press; 2018. p. 301-20.
51 Bizzari V, Dambha-Miller H, Laughaey WF, Carvalho C, Programme OE. Defining therapeutic empathy: the philosopher's view. J R Soc Med. 2019;112(3):91-5.

52 Svanaeus F. Edith Stein's phenomenology of empathy and medical ethics. In: Magrì E, Moran D, editors. Empathy, sociality, and personhood: essays on Edith Stein's phenomenological investigations. Berlin: Springer; 2017. p. 171-8.

53 Preston SD, de Waal FB. Empathy: its ultimate and proximate bases. Behav Brain Sci. 2002;25(1):1-71; discussion 20-71.

54 Szanto T, Moran D. Empathy and collective intentionality: the social philosophy of Edith Stein. Hum Stud. 2015;38(4):445-61.

55 Magrì E. Subjectivity and empathy. A Steinian approach. In: Mariani E, editor. Discipline filosofiche: figures, functions and critique of subjectivity beginning from Husserlian phenomenology; 2015. Vol. 25; p. 129-48.

56 Fernandez AV, Zahavi D. Can we train basic empathy? A phenomenological proposal. Nurse Educ Today. 2020;98:21-2.

57 Svanaeus F. The relationship between empathy and sympathy in good health care. Med Health Care Philos. 2015;18:267-77.

58 Koehler K. First rank symptoms of schizophrenia: questions concerning clinical boundaries. Br J Psychiatry. 1979;134:236-48.

59 Klosterkötter J, Gross G, Huber G, Gnad M. Bassissymptomorientierte Diagnostik schizophrener Vulnerabilität. In: Huber G, editor. Idiopathische Psychosen: Psychopathologie: Neurobiologie-Therapie. Stuttgart: Schattauer; 1990. p. 137-48.

60 Sass LA, Parnas J. Schizophrenia, consciousness, and the self. Schizophr Bull. 2003;29(3): 427-44.

61 Parnas J, Henriksen MG. Disordered self in the schizophrenia spectrum: a clinical and research perspective. Harv Rev Psychiatry. 2014;22(5):251-65.

62 Ruhrmann S, Schultze-Lutter F, Salokangas RK, Heinimaa M, Linszen D, Dingemans P, et al. Prediction of psychosis in adolescents and young adults at high risk: results from the prospective European prediction of psychosis study. Arch Gen Psychiatry. 2010;67(3):24151.

63 Schultze-Lutter F, Ruhrmann S, Fusar-Poli P, Bechdolf A, Schimmelmann BG, Klosterkötter J. Basic symptoms and the prediction of first-episode psychosis. Curr Pharm Des. 2012;18(4):351-7.

64 Parnas J, Handest P, Saebye D, Jansson L. Anomalies of subjective experience in schizophrenia and psychotic bipolar illness. Acta Psychiatr Scand. 2003;108(2):126-33.

65 Parnas J, Handest P, Jansson L, Saebye D. Anomalous subjective experience among first-admitted schizophrenia spectrum patients: empirical investigation. Psychopathology. 2005;38(5):259-67. 
66 Nordgaard J, Parnas J. Self-disorders and the schizophrenia spectrum: a study of 100 first hospital admissions. Schizophr Bull. 2014; 40(6):1300-7.

67 Ballerini A. Gerd Huber: i Sintomi Base e la riaffermazione della psicopatologia jaspersiana. In: Ballerini A, editor. Psicopatologia Fenomenologica: Percorsi di Lettura. Roma: CIC Edizioni Internazionali; 2002. p. 348-51.

68 Stanghellini G, Bolton D, Fulford WK. Person-centered psychopathology of schizophrenia: building on Karl Jaspers' understanding of patient's attitude toward his illness. Schizophr Bull. 2013;39(2):287-94.

69 Ballerini A, Rossi Monti M. La vergogna e il delirio. Torino: Bollati-Boringhieri; 1990.

70 Ballerini A. La psicopatologia tra "comprendere" e "spiegare". In: Garofalo A, Del Pistoia L, editors. Sul comprendere psicopatologico. Pisa: Edizioni ETS; 2003. p. 31-48.

71 Aragona M. The roots of psychopathological understanding: Karl Jaspers' Verstehen and the influence of Moritz Geiger's empathy. Dialogues Philos Ment Neuro Sci. 2016;9(2):36-42.

72 Stanghellini G, Aragona M. Phenomenological psychopathology: toward a person-centered hermeneutic approach in the clnical encounter. In: Stanghellini G, Aragona M, editors. An experiential approach to psychopathology. Berlin: Springer; 2016. p. 1-44.
73 Weber M. The methodology of the social sciences. New York: Free Press; 1949.

74 Schwartz MA, Wiggins OP. Diagnosis and ideal types: a contribution to psychiatric classification. Compr Psychiatry. 1987;28(4): 277-91.

75 Husserl E. Ideen zu einer reinen Phänomenologie und phänomenologischen Philosophie II, Husserliana IV. Den Haag: M. Nijhoff; 1952.

76 Schwartz MA, Wiggins OP, Norko MA. Prototypes, ideal types, and personality disorders: the return to classical psychiatry. J Pers Disord. 1989;3(1):1-9.

77 Schwartz MA, Wiggins OP. Typifications. The first step for clinical diagnosis in psychiatry. J Nerv Ment Dis. 1987;175(2):65-77.

78 Schwartz MA, Wiggins O. Science, humanism, and the nature of medical practice: a phenomenological view. Perspect Biol Med. 1985; 28:331-66.

79 Bormuth M. Karl Jaspers. In: Stanghellini G, Broome M, Raballo A, Fernandez AV, FusarPoli P, Rosfort R, editors. The Oxford handbook of phenomenological psychopathology. New York: Oxford University Press; 2019. p. 97-104.
80 Feinstein AR. An analysis of diagnostic reasoning. I. The domains and disorders of clinical macrobiology. Yale J Biol Med. 1973; 46(3):212-32.

81 Croskerry P. Clinical cognition and diagnostic error: applications of a dual process model of reasoning. Adv Health Sci Educ Theory Pract. 2009;14 Suppl 1(1):27-35.

82 Marcum JA. An integrated model of clinical reasoning: dual-process theory of cognition and metacognition. J Eval Clin Pract. 2012; 18(5):954-61.

83 Monteiro SM, Norman G. Diagnostic reasoning: where we've been, where we're going. Teach Learn Med. 2013;25:S26-S32.

84 Husserl E. Logische Untersuchungen. 2nd ed. Tübingen: Niemeyer; 1913.

85 Richir M. De l'analyse phénoménologique comme démarche en zig-zag. Actes du colloque franco-peruvien "La notion d'analyse". Toulouse: Presses Universitaires du Mirail; 1991. p. 141-60.

86 Sholokhova S. Benefits and challenges of the phenomenological approach to the psychiatrist's subjective experience: impassivity, neutrality, and embodied awareness in the clinical encounter. Philos Psychiatr Psychol. 2019; 26(4):E83-96. 